Check for updates

Cite this: RSC Adv., 2018, 8, 34960

\title{
Anion influences on reactivity and NMR spectroscopic features of NHC precursors $\dagger$
}

\author{
Han Vinh Huynh, (D) * Truc Tien Lam and Huyen T. T. Luong \\ A series of 16 benzimidazolium salts of the type ${ }^{i} \mathrm{Pr}_{2}-$ bimy $^{+} \mathrm{X}^{-}$with various anions $\mathrm{X}$ were synthesized and \\ characterized by various spectroscopic and spectrometric methods. Significant anion and solvent effects \\ on the chemical shifts of the $\mathrm{C} 2-\mathrm{H}$ protons were found, which allows for a ranking of the anions in \\ terms of their hydrogen-bond acceptor properties. Stronger acceptors could increase the acidity of their \\ respective salts leading to a faster $H / D$ exchange. Similar but less pronounced anion influences were \\ detected for the ${ }^{13} \mathrm{C}_{\mathrm{C} 2}$ NMR resonances, while ${ }^{1} \mathrm{~J}_{\mathrm{C} 2-\mathrm{H}}$ coupling constants appear to be anion and solvent \\ independent.
}

Received 9th July 2018

Accepted 6th October 2018

DOI: $10.1039 / c 8 r a 05839 c$

rsc.li/rsc-advances

\section{Introduction}

$\mathrm{N}-\mathrm{Heterocyclic}$ carbenes (NHCs) and their complexes are nowadays ubiquitous in the areas of catalysis and organometallic chemistry. ${ }^{1-5}$ Most conveniently, they are accessed by deprotonation of azolium salts differing in backbones and substituents. The structural diversity allows certain control over the stereoelectronic properties of the respective NHCs. Thus, detailed knowledge of the properties and preparative routes to these most common precursors is imperative for NHC chemistry. ${ }^{6}$ One general synthetic pathway involves double $N$-alkylation of azoles using electrophiles such as alkyl halides and oxonium salts. In such $\mathrm{S}_{\mathrm{N}} 2$ reactions, azolium salts are routinely obtained which contain either different halides (e.g. $\left.\mathrm{Cl}^{-}, \mathrm{Br}^{-}, \mathrm{I}^{-}\right)$or weakly coordinating species (e.g. $\left.\mathrm{BF}_{4}^{-}, \mathrm{PF}_{6}{ }^{-}\right)$as counteranions. Many of such compounds are also ionic liquids, and it is well known that anions influence the physical properties of the salts, e.g. melting point and solubility. Moreover, the influence of substituents and the heterocyclic backbone on the acidities of azolium salts have also been established. ${ }^{7,8}$ Systematic studies detailing the comparison between different anions of a given cation and their influences on reactivity and spectroscopic characteristics are surprisingly rare. A recent study suggests that anion effects are negligible in dimethylsulfoxide ${ }^{8}$ or in water. ${ }^{9}$ However, most NHC chemistry is conducted in organic solvents, and we hypothesize that counteranions could affect the acidity of an azolium cation. For example, we have observed that direct

Department of Chemistry, National University of Singapore, 3 Science Drive 3, 117543 Singapore, Republic of Singapore. E-mail: chmhhv@nus.edu.sg; Fax: 656779 1691; Tel: +6565162670

$\dagger$ Electronic supplementary information (ESI) available: Full experimental details, selected crystallographic data. CCDC 1853200, 1853201 and 1867791. For ESI and crystallographic data in CIF or other electronic format see DOI: $10.1039 / \mathrm{c} 8 \mathrm{ra0} 5839 \mathrm{c}$ metalation of azolium salts with weakly coordinating anions (e.g. $\mathrm{BF}_{4}{ }^{-}, \mathrm{PF}_{6}{ }^{-}$) is difficult even under harsh conditions, but with addition of halides the reaction proceeds at ambient temperature. ${ }^{10,11}$ Such anion effects have also been observed in catalysis where the active metal-NHC species is prepared in situ from azolium precursors. Again, halide salts were much more effective than the respective tetrafluoroborates, which could be due to their increased acidity facilitating NHC complex formation. ${ }^{12,13}$ As part of our broader research program on NHCs and in contribution to a more detailed understanding of NHC precursors and ionic liquids in general, we herein report a detailed spectroscopic profiling on such anion influences in selected common organic solvents.

\section{Results and discussion}

Syntheses and characterizations of ${ }^{\mathrm{i}} \mathrm{Pr}_{2}-\mathrm{bimyH}^{+} \mathrm{X}^{-}$salts

The proposed study on anion influences in NHC precursors calls for the preparation of various azolium salts that contain the same heterocyclic cation, but differ in the counteranion. The question thus arises, which heterocyclic system would be best for our purpose. Among the types of classical azolium salts depicted in Chart 1 , we decided to explore the $N, N$-dialkylbenzimidazolium system III, because (i) their preparation is easy, and (ii) they contain only one acidic proton in the fivemembered ring system, which should simplify the study.

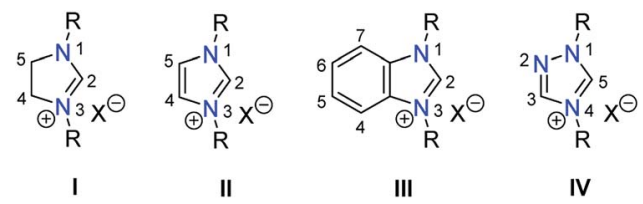

Chart 1 Classical azolium salts for the most common NHCs and their numbering scheme. 
In particular, 1,3-diisopropylbenzimidazolium bromide (A) ${ }^{14}$ is regularly used in our laboratories to prepare NHC complexes for donor strength determination using the HEP system. ${ }^{15-18}$ Using this selected salt as the starting point a series of anion exchange reactions were conducted, which led to 16 new benzimidazolium salts as summarized in Scheme 1.

The preparation of salts $\mathbf{B}-\mathbf{G}$ was most straightforward, and simply involved exposure of compound $\mathbf{A}$ to a slight excess of sodium or potassium salts containing the desired anion at ambient temperature (AT). In general, the comparatively big azolium cations favour larger anions $\left(\right.$ e.g. $\left.\mathrm{PF}_{6}{ }^{-}\right)$, while small alkali metals form more stable salts with small anions (e.g. halides) due to better interionic interactions (e.g. lattice energy). The precipitation of sodium or potassium bromide from acetone drives these reactions forward. However, the same approach could not be applied for the synthesis of $\mathbf{H}-\mathbf{K}$, where silver salts had to be employed instead. The more favourable formation of silver bromide drove anion exchange to completion. More difficult was the synthesis of the acetate $\mathbf{L}$. Reaction of salt $\mathbf{A}$ with sodium acetate did not occur, while its treatment with silver(I) acetate led to in situ deprotonation to afford a silver(I)-NHC complex instead. Eventually, salt $\mathbf{L}$ could be prepared by prolonged heating species $\mathbf{A}$ with zinc(II) acetate in dichloromethane under reflux.

The replacement of bromide with lighter halides is difficult (vide supra), and often require ion-exchange resins. However, such anion exchange can also be achieved by exploiting the

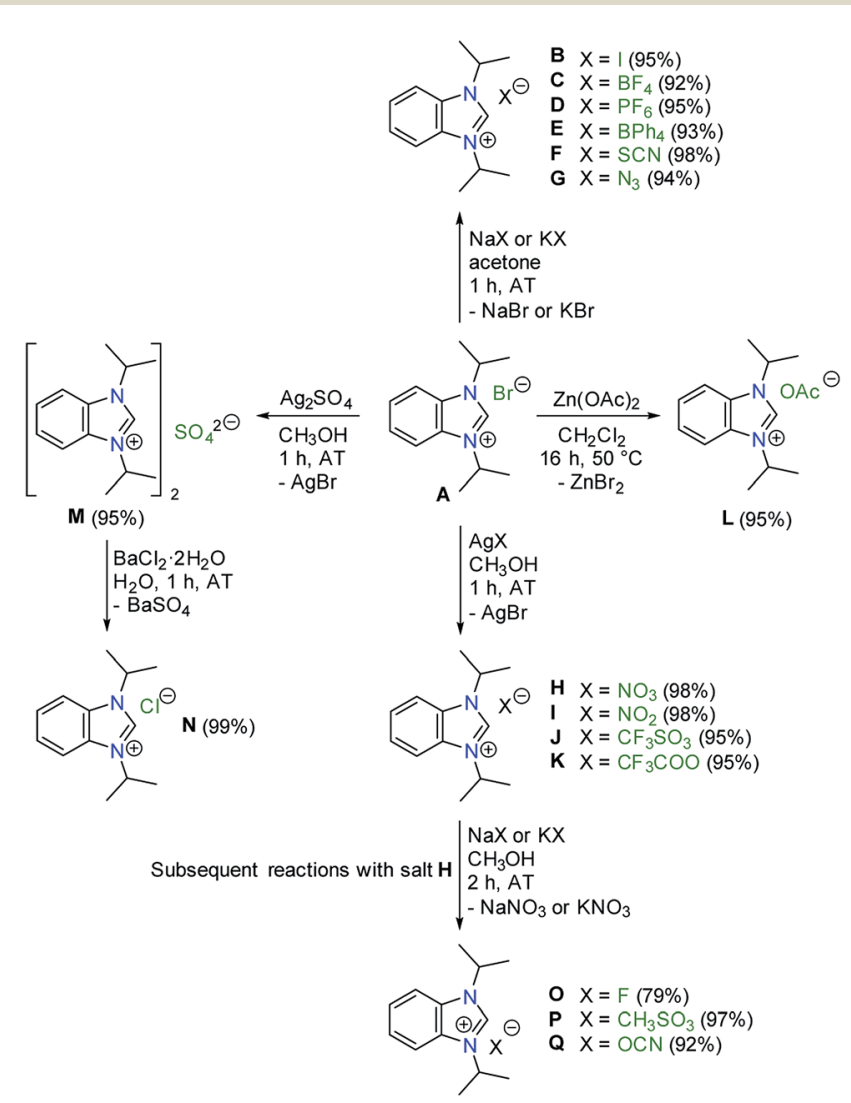

Scheme 1 Preparative routes to benzimidazolium salts with diverse counteranions.

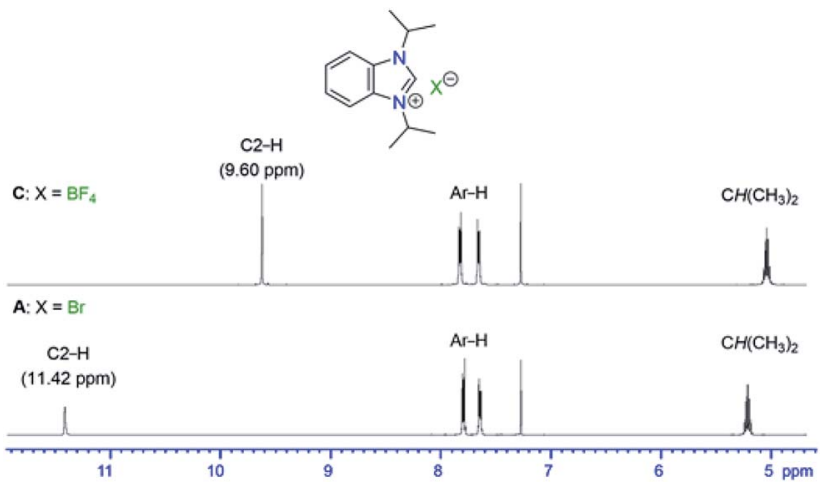

Fig. $1{ }^{1} \mathrm{H}$ NMR spectroscopic comparison of $\mathrm{BF}_{4}{ }^{-} \mathrm{vs}$. $\mathrm{Br}^{-}$salts in the range from $12-4 \mathrm{ppm}$.

solubilities of common salts. This approach was demonstrated in the 2-step preparation of the chloride N. First, the bromide in salt A was precipitated as silver bromide using silver(I) sulfate to afford the bis(benzimidazolium) sulfate M. Subsequently, the sulfate anion can be easily precipitated as barium(II) sulfate using an aqueous solution of barium(II) chloride to give salt $\mathbf{N}$ as a hygroscopic solid. The very favourable formation of insoluble barium(II) sulfate drives this reaction.

Finally, the salts $\mathbf{O}-\mathbf{Q}$ were prepared in a similar manner by reaction of the nitrate $\mathbf{H}$ with sodium or potassium salts containing the desired anions.

All salts B-Q were all obtained as white to off-white powders and characterized by NMR spectroscopy. Their formations were confirmed by the significant shifts of the $\mathrm{C} 2-\mathrm{H}$ signals compared to the starting material A. In addition, new NMR signals arising from the newly introduced anions were found for $\mathbf{C}, \mathbf{D}, \mathbf{E}, \mathbf{F}, \mathbf{J}, \mathbf{K}, \mathbf{L}, \mathbf{P}$ and $\mathbf{Q}$. Apart from the $\mathrm{C} 2-\mathrm{H}$ signals, there were little changes of other ${ }^{1} \mathrm{H}$ NMR signals of the ${ }^{\mathrm{i}} \mathrm{Pr}_{2}-\mathrm{bimyH}^{+}$ cations in these salts. Fig. 1 depicts a representative comparison of the ${ }^{1} \mathrm{H}$ NMR spectra between the bromide salt $\mathbf{A}$ and the tetrafluoroborate salt $\mathrm{C}$ in the range from 12-4 ppm.

Moreover, ESI mass spectrometry was also employed as a viable method, especially for salts with heavier anions, to determine the compositions of the newly synthesized salts. Apparently, all new salts show the same base peak at $m / z=203$ for the $\left[{ }^{\mathrm{i}} \mathrm{Pr}_{2} \text {-bimyH }\right]^{+}$cation in the positive-ion mode. Peaks attributed to the anions could also be observed in the case of $\mathbf{B}$ $(\mathrm{X}=\mathrm{I} ; m / z=127), \mathbf{D}\left(\mathrm{X}=\mathrm{PF}_{6} ; m / z=145\right), \mathbf{E}\left(\mathrm{X}=\mathrm{BPh}_{4} ; m / z=\right.$ $319)$ and $\mathbf{J}\left(\mathrm{X}=\mathrm{CF}_{3} \mathrm{SO}_{3} ; m / z=149\right)$ in the negative-ion mode. Furthermore, peaks assignable to the $[2 \mathrm{M}-\mathrm{X}]^{+}$fragments were also observed for the three salts bearing comparatively big anions, i.e. $\mathbf{D}\left(\mathrm{X}=\mathrm{PF}_{6} ; m / z=551\right), \mathbf{E}\left(\mathrm{X}=\mathrm{BPh}_{4} ; m / z=725\right)$ and $\mathbf{J}$ $\left(\mathrm{X}=\mathrm{CF}_{3} \mathrm{SO}_{3} ; m / z=555\right)$ pointing to their greater tendencies to form ion pairs in the gas phase.

In addition, single crystals of $\mathbf{E}, \mathbf{F}$ and $\mathbf{N} \cdot \mathrm{H}_{2} \mathrm{O}$ suitable for $\mathrm{X}$ ray diffraction were obtained by slow evaporation of their solutions in dichloromethane/hexane (E, F) and dichloromethane/ethyl acetate $\left(\mathbf{N} \cdot \mathrm{H}_{2} \mathrm{O}\right)$. Fig. 2 depicts the molecular structures of these three salts. As anticipated, the bond lengths and angles within the ${ }^{\mathrm{i}} \mathrm{Pr}_{2}$-bimyH ${ }^{+}$cations of all three salts are typical and do not vary much from those of their 


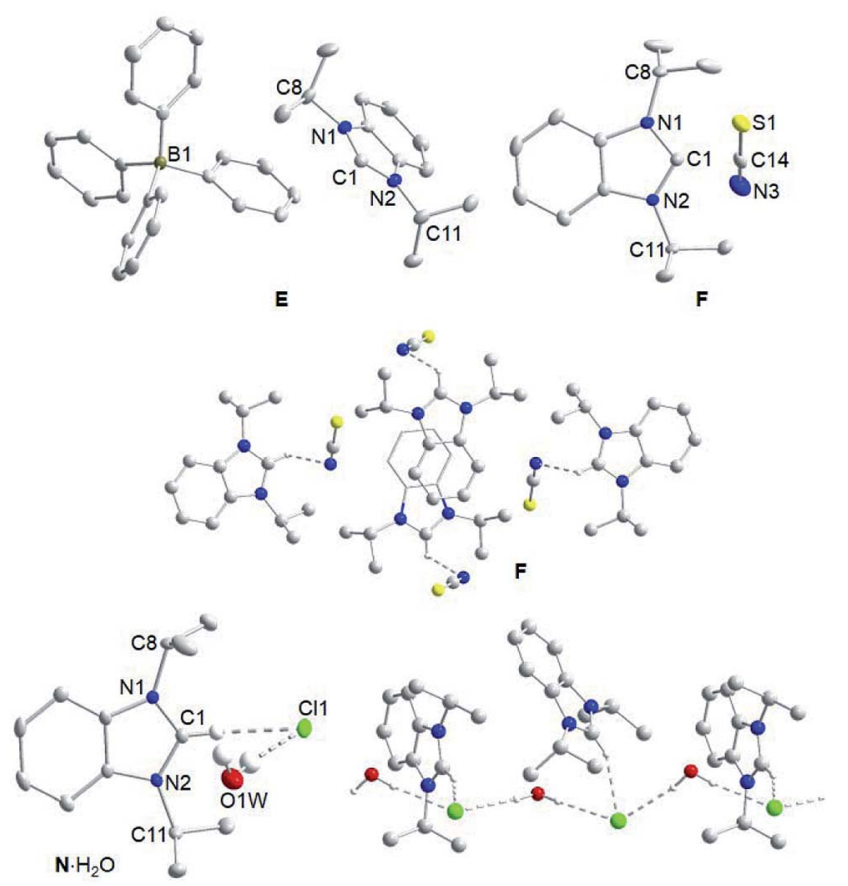

Fig. 2 Molecular structures of $\mathrm{E}, \mathrm{F}$ and $\mathrm{N} \cdot \mathrm{H}_{2} \mathrm{O}$ showing $50 \%$ probability ellipsoids; hydrogen atoms are omitted for clarity with exception of those engaged in hydrogen bonding. Selected bond lengths $[\AA \AA]$ and bond angles [deg]: E, C1-N1 1.328(3), C1-N2 1.326(3), N1-C8 1.485(3), N2-C11 1.490(2); N1-C1-N2 110.8(2). F, C1-N1 1.335(2), C1-N2 1.331(2), N1-C8 1.485(2), N2-C11 1.485(2), S1-C14 1.646(2), N3-C14 1.154(3); N1-C1-N2 110.6(2), S1-C14-N3 179.0(2). N. $\mathrm{H}_{2} \mathrm{O}, \mathrm{C} 1-\mathrm{N} 1$ $1.329(3), \mathrm{C} 1-\mathrm{N} 21.336(2), \mathrm{N} 1-\mathrm{C} 81.488(3), \mathrm{N} 2-\mathrm{C} 11$ 1.488(3); N1-C1N2 110.5(2).

starting material $\mathbf{A .}^{\mathbf{1 4}}$ For salt $\mathbf{E}$, no apparent cation-anion interactions can be found in the solid state molecular structure. Salt F, however, shows short contacts of 2.695(2) A between the nitrogen of the anion with the $\mathrm{C} 2-\mathrm{H}$ proton of the cation and a C-H $\cdots$ NCS angle of $107.4(1)^{\circ}$. Despite several attempts, it was not possible to crystallize salt $\mathbf{N}$ without water, since it is very hygroscopic. Instead, we obtained crystals of the solvate $\mathbf{N} \cdot \mathrm{H}_{2} \mathrm{O}$. Despite the water molecule, hydrogen bonding of the chloride to the $\mathrm{C} 2-\mathrm{H}$ proton with a separation of 2.4982(7) $\AA$ and a C-H $\cdots$ $\mathrm{Cl}$ angle of $155.0(1)^{\circ}$ is apparent. In addition, the chloride engages in two hydrogen bonds with water with distances of 2.43(4) and 2.49(4) $\AA$ and angles of 167(3) and 172(4) ${ }^{\circ}$, respectively. The latter leads to a chain-like arrangement of the salts in solid state.

\section{Anion influence on C2-H NMR chemical shifts and IR bands of ${ }^{\mathrm{i}} \mathrm{Pr}_{2}$-bimyH ${ }^{+} \mathbf{X}^{-}$salts}

Hydrogen bonding has been recognized as a main interaction between the cations and anions of azolium salts leading to close arrangement between the counteranions and the most acidic C2-H proton. ${ }^{19-22}$

However, this type of interaction can be affected by many factors, such as functional groups attached to the cation as well as solvents and concentrations used for measuring. In order to investigate only anion influences, all salts in our study contain the same ${ }^{\mathrm{i}} \mathrm{Pr}_{2}$-bimyH ${ }^{+}$cation, which bears innocent and inert $N$ -
Table 1 NMR and IR spectroscopic data for the $\mathrm{C} 2-\mathrm{H}$ function of salts $\mathrm{A}-\mathrm{L}$ and $\mathrm{N}-\mathrm{Q}$

\begin{tabular}{lllll}
\hline Salt & $\mathbf{X}$ & ${ }^{1} \mathrm{H}_{\mathrm{C} 2-\mathrm{H}}{ }^{a}[\mathrm{ppm}]$ & ${ }^{13} \mathrm{C}_{\mathrm{C} 2}{ }^{a}[\mathrm{ppm}]$ & $\tilde{\nu}_{\mathrm{C} 2-\mathrm{H}}{ }^{b}\left[\mathrm{~cm}^{-1}\right]$ \\
\hline $\mathbf{N}$ & $\mathrm{Cl}$ & 11.68 & 142.1 & 2983 \\
$\mathbf{A}$ & $\mathrm{Br}$ & 11.42 & 141.3 & 2983 \\
$\mathbf{O}$ & $\mathrm{F}$ & 11.10 & 142.0 & 2982 \\
$\mathbf{B}$ & $\mathrm{I}$ & 10.92 & 140.4 & 2985 \\
$\mathbf{G}$ & $\mathrm{N}_{3}$ & 10.89 & 141.1 & 2979 \\
$\mathbf{I}$ & $\mathrm{NO}_{2}$ & 10.84 & 140.3 & 2981 \\
$\mathbf{Q}$ & $\mathrm{OCN}$ & 10.71 & 141.2 & 2984 \\
$\mathbf{H}$ & $\mathrm{NO}_{3}$ & 10.70 & 139.7 & 2988 \\
$\mathbf{P}$ & $\mathrm{CH}_{3} \mathrm{SO}_{3}$ & 10.67 & 141.7 & 2989 \\
$\mathbf{F}$ & $\mathrm{SCN}_{\mathbf{L}}$ & 10.50 & 140.5 & 2980 \\
$\mathbf{J}$ & $\mathrm{CH}_{3} \mathrm{CO}_{2}$ & 9.98 & 139.8 & 2982 \\
$\mathbf{K}$ & $\mathrm{CF}_{3} \mathrm{SO}_{3}$ & 9.78 & 138.5 & 2982 \\
$\mathbf{C}$ & $\mathrm{CF}_{3} \mathrm{CO}_{2}$ & 9.71 & 138.7 & 2983 \\
$\mathbf{D}$ & $\mathrm{BF}_{4}$ & 9.60 & 139.2 & 2995 \\
$\mathbf{E}$ & $\mathrm{PF}_{6}$ & 9.17 & 138.5 & 2996 \\
$\mathrm{BPh}_{4}$ & 8.99 & 139.6 & 2985
\end{tabular}

${ }^{a}$ Measured in $\mathrm{CDCl}_{3}$ at concentrations of $83 \mu \mathrm{mol} \mathrm{mL}{ }^{-1}$ and internally referenced to the residual protio-solvent signal at 7.26 and $77.7 \mathrm{ppm}$ relative to TMS, respectively. ${ }^{b}$ Data was collected by ATR methodology with solid sample.

isopropyl substituents. Since azolium salts are notoriously hygroscopic, they were dried under vacuum for a prolonged time (1 day) to remove as much water as possible. The very hygroscopic salt $\mathbf{N}$ was dried under vacuum at $120{ }^{\circ} \mathrm{C}$ for 5 hours. In some cases, complete removal of crystal water was not possible, and the effect of trace water was investigated separately with the parent salt $\mathbf{A}$ (vide infra). The dried salts were initially measured in $\mathrm{CDCl}_{3}$ at room temperature at a concentration of $83 \mu \mathrm{mol} \mathrm{mL}{ }^{-1}$, in order to eliminate any other effects that could affect the cation-anion interaction. Table 1 summarizes the ${ }^{1} \mathrm{H}_{\mathrm{C} 2-\mathrm{H}}$ as well as ${ }^{13} \mathrm{C}_{\mathrm{C} 2}$ NMR resonances for salts $\mathbf{A}-\mathbf{Q}$, with the exception of $\mathbf{M}$, which bears the less comparable dianionic sulfate anion. The IR data for the $\mathrm{C} 2-\mathrm{H}$ vibration has also been included for comparison. The ${ }^{1} \mathrm{H}_{\mathrm{C} 2-\mathrm{H}}$ NMR signals of the 16 salts cover chemical shifts from 8.9911.68 ppm, which supposedly reflects a diverse strength of hydrogen bonding of the anions.

We anticipate that a stronger hydrogen bond acceptor would also polarize the $\mathrm{C} 2-\mathrm{H}$ bond more, thus slightly increasing the acidity of the salt. As expected, halide anions with four lone pairs of electrons are the best hydrogen bonding acceptors that lead to the most downfield shifts of the ${ }^{1} \mathrm{H}_{\mathrm{C} 2-\mathrm{H}}$ signal The gradual downfield shifts from 10.92 (I), 11.42 (Br) to $11.68 \mathrm{ppm}$ (Cl) reflects the increasing electronegativity of the halogens in the order of $\mathrm{I}<\mathrm{Br}<\mathrm{Cl}$.

However, the fluoride salt $\mathbf{O}$ does not follow this trend with an intermediate ${ }^{1} \mathrm{H}_{\mathrm{C} 2-\mathrm{H}} \mathrm{NMR}$ resonance of $11.10 \mathrm{ppm}$. In fact, the relative position of the fluoride among the halides is not clear and difficult to determine..$^{23,24}$ Intuitively, the highly electronegative and small-sized fluoride is thought to be a superior hydrogen bond acceptor. Instead, this study places its hydrogen bonding capability with the ${ }^{\mathrm{i}} \mathrm{Pr}_{2}$-bimyH $\mathrm{H}^{+}$donor in between that of the bromide and iodide anions. Notably, it has been reported that intramolecular hydrogen bonding of 2-halophenols 
decrease in the order $\mathrm{F} \approx \mathrm{Cl}>\mathrm{Br}>\mathrm{I}$ in the vapour phase, while the order in solution is $\mathrm{Cl}>\mathrm{Br}>\mathrm{F} \approx \mathrm{I}^{\mathbf{2 4 , 2 5}}$ The latter is in agreement with our results. It has been suggested that the highly electronegative fluorine holds onto its electron lone pairs so tightly that charge transfer from the non-bonding orbital of fluorine $\left(n_{\mathrm{F}}\right)$ to the anti-bonding orbital of the $\mathrm{C} 2-\mathrm{H}$ interaction $\left(\sigma_{\mathrm{C} 2-\mathrm{H}}^{*}\right)$ cannot occur properly at a certain distance. ${ }^{26}$ Therefore, the ability to form hydrogen bonding of fluoride anion could be reduced compared to its intuitively expected value.

The substitution of other groups with fluorine can affect the hydrogen-bonding capability of an anion as well. For example, the acetate anion of $\mathbf{L}$ and methanesulfonate anion of $\mathbf{P}$ are stronger hydrogen bonding acceptors compared to their fluorine-substituted analogues $\mathbf{K}$ and $\mathbf{J}$, respectively. The negative inductive $(-I)$ effects exerted by the three fluorine atoms withdraw electrons and decrease the hydrogen bonding capability of the anions as a whole.

It is also our interest to analyse the different effects of linear triatomic anions, such as $\mathrm{SCN}^{-}, \mathrm{OCN}^{-}$and $\mathrm{N}_{3}{ }^{-}$. The influence of these pseudohalides was anticipated to be very similar, yet they can be differentiated by the ${ }^{1} \mathrm{H}_{\mathrm{C} 2-\mathrm{H}}$ NMR chemical shifts of their salts. For ambivalent species, it has been noted that nitrogen are superior acceptors than oxygen atoms. ${ }^{27}$ Sulfur is expected to be a poorer acceptor than oxygen due to its larger size, which weakens interactions with the much smaller hydrogen atoms ( $c f$. Fig. 2).

All three anions can be represented by simple resonance structures (taught in classes), which are depicted in Fig. 3 along with the calculated Mulliken charges. The more favourable resonance form of the $\mathrm{N}_{3}{ }^{-}$anion contains two negative charges at two terminal nitrogen atoms, which should result in greater ability to form hydrogen bonds. Salt $\mathbf{G}$ indeed shows the most downfield ${ }^{1} \mathrm{H}_{\mathrm{C} 2-\mathrm{H}}$ NMR signal of $10.89 \mathrm{ppm}$ in comparison to its counterparts. The preferred resonance structure for $\mathrm{OCN}^{-}$ anion has the negative charge on the oxygen atom with three lone pairs of electrons, which is reflected in the Mulliken charge as well. For the $\mathrm{SCN}^{-}$anion, the favourable resonance form places the negative charge on the nitrogen atom with only two lone pairs ( $c f$. Fig. 2). Therefore, the former is expected to be a slightly better hydrogen bond acceptor. Notably, the ${ }^{1} \mathrm{H}_{\mathrm{C} 2-\mathrm{H}}$ NMR resonances of $10.71\left(\mathrm{OCN}^{-}\right)$and $10.50 \mathrm{ppm}\left(\mathrm{SCN}^{-}\right)$ recorded for salts $\mathbf{Q}$ and $\mathbf{F}$, respectively, are in line with this

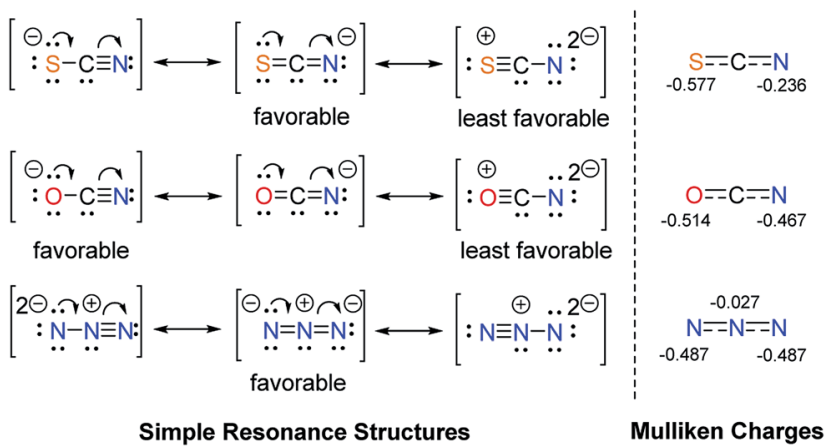

Fig. 3 Resonance structures and calculated Mulliken charges of the pseudohalides $\mathrm{SCN}^{-}, \mathrm{OCN}^{-}$and $\mathrm{N}_{3}^{-}$.

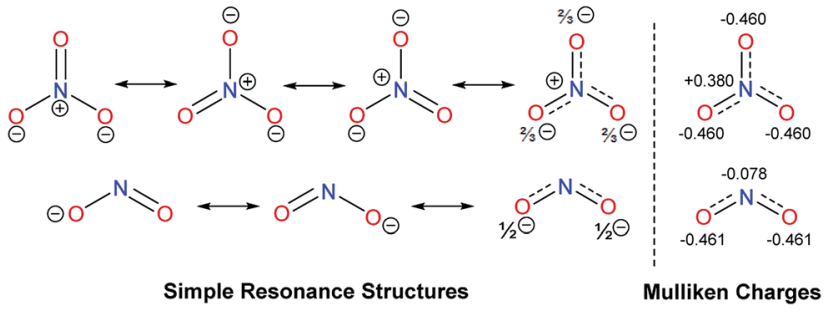

Fig. 4 Resonance structures and calculated Mulliken charges of $\mathrm{NO}_{3}{ }^{-}$ and $\mathrm{NO}_{2}^{-}$anions.

argument. Nevertheless, it could be more accurate to compare the calculated Mulliken charges at nitrogen, since nitrogen was reported to be a more dominant acceptor than oxygen or sulfur. The Mulliken charges at nitrogen decrease in the order $\mathrm{N}_{3}{ }^{-}>$ $\mathrm{OCN}^{-}>\mathrm{SCN}^{-}$, which could explain the upfield shifts of the $\mathrm{C} 2-$ $\mathrm{H}$ protons of the respective salts in the same order.

Similar considerations can be used to rationalize differences between nitrate salt $\mathbf{H}(10.70 \mathrm{ppm})$ and the nitrite salt $\mathbf{I}$ (10.84 ppm). On average, each of the three oxygen atoms in the 'delocalized' $\mathrm{NO}_{3}{ }^{-}$anion retains two thirds of the negative charge, which can be used to interact with the benzimidazolium C2-H proton (Fig. 4). However, there is also a positive charge at nitrogen in all resonance forms, which is reflected in the Mulliken charge.

The two oxygen atoms of the $\mathrm{NO}_{2}{ }^{-}$anion, on the other hand, have one-half of the negative charge for such an interaction. Here, there is no positive charge at the central nitrogen. The calculation even indicates a small negative Mulliken charge at nitrogen, while the charge at oxygen is essentially identical to that of the $\mathrm{NO}_{3}{ }^{-}$anion. Therefore, $\mathrm{NO}_{2}{ }^{-}$anion could be considered as a better hydrogen bonding acceptor than $\mathrm{NO}_{3}{ }^{-}$ anion, which is supported by ${ }^{1} \mathrm{H}$ NMR spectroscopy.

Finally, the salts $\mathbf{C}, \mathbf{D}, \mathbf{J}$ and $\mathbf{K}$ containing the weakly coordinating anions $\mathrm{BF}_{4}{ }^{-}, \mathrm{PF}_{6}{ }^{-}, \mathrm{CF}_{3} \mathrm{SO}_{3}$ and $\mathrm{CF}_{3} \mathrm{CO}_{2}{ }^{-}$, respectively, show the most upfield $\mathrm{C} 2-\mathrm{H}^{1} \mathrm{H}$ NMR signals. This observation lends support to the notion that they can hardly form strong hydrogen bonds. The $\mathrm{BPh}_{4}{ }^{-}$ion in salt $\mathbf{E}$ represents a special case, where the downfield shift cannot be used to estimate hydrogen bonding. Here, it has been reported that stronger hydrogen bonding leads to an upfield shift instead. This is so, since stronger interactions would place the $\mathrm{C} 2-\mathrm{H}$ proton closer to the shielding area of the phenyl substituents of the borate anion. ${ }^{28}$ Overall, the ${ }^{1} \mathrm{H}$ NMR resonances of $\mathrm{C} 2-\mathrm{H}$ proton in most ${ }^{\mathrm{i}} \mathrm{Pr}_{2}$-bimyH ${ }^{+} \mathrm{X}^{-}$salts can be used to rank the effects of monoanions on the ${ }^{1} \mathrm{H}$ NMR spectroscopic scale (Fig. 5).

As mentioned above, many azolium salts are hygroscopic, and it can be rather difficult to remove all traces of water from the crystal lattice. Thus, we studied the effects of water on the ${ }^{1} \mathrm{H}_{\mathrm{C} 2-\mathrm{H}}$ NMR chemical shifts of salt $\mathbf{A}$ as a representative. Fig. 6 depicts the ${ }^{1} \mathrm{H}$ NMR spectroscopic changes of the bromide salt $\mathbf{A}$ in $\mathrm{CDCl}_{3}$ upon addition of 1-3 equivalents of water. In the presence of one equivalent of water (b), a slightly more upfield NMR signal for the $\mathrm{C} 2-\mathrm{H}$ proton can be noted compared to the water-free sample (a), while all other signals remain essentially unchanged. Addition of another equivalent induces a smaller upfield change, while addition of a third equivalent appears to 


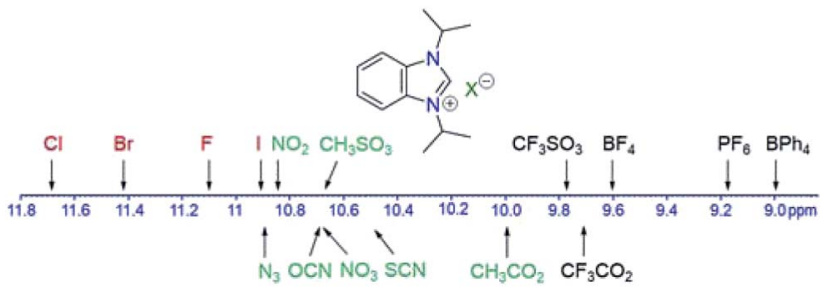

Fig. $5{ }^{1} \mathrm{H}_{\mathrm{C} 2-\mathrm{H}}$ NMR chemical shifts of benzimidazolium salts with different anions.

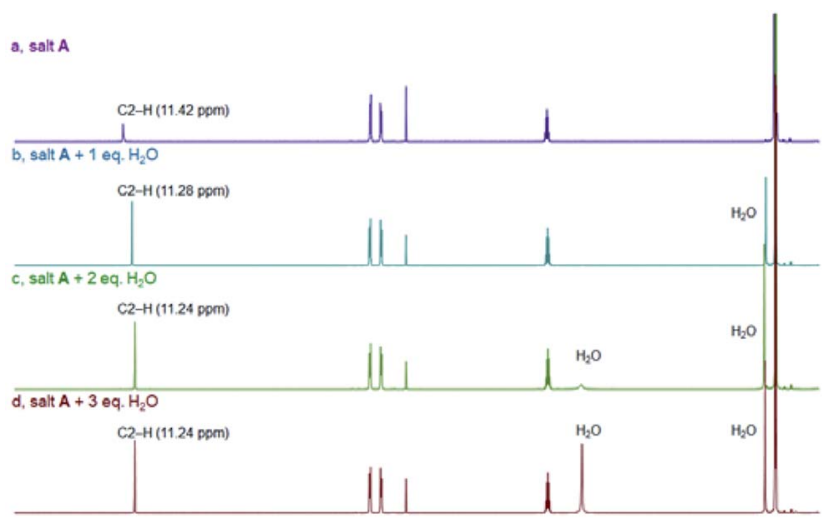

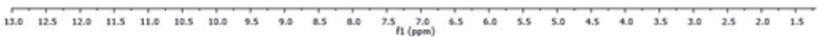

Fig. 6 Changes of the ${ }^{1} \mathrm{H}$ NMR spectrum of salt $\mathrm{A}$ in $\mathrm{CDCl}_{3}$ upon addition of $1-3$ equivalents of water.

have little further effect on the $\mathrm{C} 2-\mathrm{H}$ signal. The presence of water reduces interaction of the bromide with the azolium cation. Instead, more favourable and competing bromide-water interactions kick in. As expected, a new signal due to water starts to appear. Interestingly, a second water signal surfaces in spectrum (c), which becomes very apparent in spectrum (d). This observation indicates the presence of unsymmetrical water molecules. It appears that with excess of water only one of the two water hydrogen atoms can efficiently engage in hydrogen bonding giving rise to two well separated signals. Thus, water competes efficiently with the azolium cation for good hydrogenbond acceptors leading to an upfield shift of the $\mathrm{C} 2-\mathrm{H}$ signal.

According to the ${ }^{13} \mathrm{C}$ NMR data listed in Table 1, the influence of the anions on the $\mathrm{C} 2$ carbon signals is less pronounced. This is not entirely surprising since the C2-carbon atom is overall further away and "indirectly" affected by the anion. Nevertheless, salts with strong and moderate hydrogen bond acceptors gave more downfield ${ }^{13} \mathrm{C}_{\mathrm{C} 2} \mathrm{NMR}$ signals ranging from 140.3-142.1 ppm, while those with weaker ones resonate at more upfield regions from 138.5-139.2 ppm. Again, the $\mathrm{BPh}_{4}{ }^{-}$ ion is a special case, since the chemical shift of $139.6 \mathrm{ppm}$ for its salt suggests a stronger acceptor compared to ${ }^{1} \mathrm{H}$ NMR data.

In addition to NMR studies, we also have also determined the $\mathrm{C} 2-\mathrm{H}$ stretches of the salts by IR spectroscopy. In general, a smaller wavenumber indicates a weaker $\mathrm{C}-\mathrm{H}$ bond. However, comparison of the relevant data is less conclusive, and a clear trend is absent. IR spectroscopy cannot reveal smaller differences between halides and pseudohalides due to its insufficient resolution. ${ }^{29}$ However, one piece of information that can be extracted from the data is that halide salts have notably smaller wavenumbers than their $\mathrm{BF}_{4}{ }^{-}$or $\mathrm{PF}_{6}{ }^{-}$counterparts, which is within expectations. Notably, the IR data for the $\mathrm{BPh}_{4}{ }^{-}$salt appears to be in line with its ${ }^{13} \mathrm{C}$ NMR data.

Finally, four salts $\mathbf{A}-\mathbf{C}$ and $\mathbf{N}$ with common anions $(\mathrm{Cl}, \mathrm{Br}, \mathrm{I}$ and $\mathrm{BF}_{4}$ ) in NHC chemistry were chosen to study the conductivity of their equimolar solutions in chloroform. Strong ion pairs are expected to have lower conductivity, while solvated ions would give larger values. The chloride (N) and bromide (A) salts showed the lowest conductivity of 1.8 and $2.5 \mu \mathrm{S} \mathrm{cm}{ }^{-1}$, respectively, which could reflect their tendency to form ion pairs via hydrogen bonds. The salts with the larger iodide and tetrafluoroborate anions show conductivities of 5.1 and $4.1 \mu \mathrm{S} \mathrm{cm}^{-1}$, respectively. It appears that larger anions can interact less efficiently with the small C2-H hydrogen leading to a larger separation of cation and anion in solution. Nevertheless, this study only provides a qualitative argument.

\section{Solvent and anion influence on chemical shifts and ${ }^{1} J_{\mathrm{C}-\mathrm{H}}$ coupling constants}

Next, solvent effects on the ${ }^{1} \mathrm{H}$ and ${ }^{13} \mathrm{C}$ NMR signals of the $\mathrm{C} 2-\mathrm{H}$ group were studied. Equimolar solutions of nine selected salts $\mathbf{A}-\mathbf{F}, \mathbf{H}, \mathbf{I}$ and $\mathbf{N}$ in $\mathrm{CD}_{3} \mathrm{CN}$ and DMSO- $d_{6}$ as two common polar deuterated solvents were subjected to NMR spectroscopy and the results compared to the data obtained in $\mathrm{CDCl}_{3}$. The respective protio-solvents have polarity indexes of 4.1 (chloroform), 5.8 (acetonitrile) and 7.2 (dimethylsulfoxide), respectively.

Table 2 summarizes the ${ }^{1} \mathrm{H}$ NMR resonances in decreasing order $\left(\mathrm{CDCl}_{3}\right)$ observed in different solvents. It becomes apparent, that the chemical shift differences among the salts are most pronounced in $\mathrm{CDCl}_{3}(\Delta \delta 2.69 \mathrm{ppm})$ as the least polar solvent. With increasing solvent polarity, the resonances of the four salts become more and more similar $\left(\mathrm{CD}_{3} \mathrm{CN}: \Delta \delta 1.50\right.$ $\mathrm{ppm})$. The smallest differences are observed in DMSO- $d_{6}(\Delta \delta 0.3$ $\mathrm{ppm})$, which can engage best in hydrogen bonds. As such, the interactions with each individual anion becomes less significant, and very similar chemical shifts are thus obtained. In $\mathrm{CDCl}_{3}$ as the worst hydrogen bond acceptor, the anion

Table $2{ }^{1} \mathrm{H}_{\mathrm{C} 2-\mathrm{H}}$ NMR signals of salts $\mathrm{A}-\mathrm{F}, \mathrm{H}, \mathrm{I}$ and $\mathrm{N}$ in different solvents ${ }^{a}$

\begin{tabular}{llrrr}
\hline Salt & $\mathrm{X}$ & $\mathrm{CDCl}_{3}$ & $\mathrm{CD}_{3} \mathrm{CN}$ & DMSO- $d_{6}$ \\
\hline $\mathbf{N}$ & $\mathrm{Cl}$ & $11.68 \mathrm{ppm}$ & $10.38 \mathrm{ppm}$ & $10.04 \mathrm{ppm}$ \\
$\mathbf{A}$ & $\mathrm{Br}$ & $11.42 \mathrm{ppm}$ & $9.96 \mathrm{ppm}$ & $9.91 \mathrm{ppm}$ \\
$\mathbf{B}$ & $\mathrm{I}$ & $10.92 \mathrm{ppm}$ & $9.35 \mathrm{ppm}$ & $9.79 \mathrm{ppm}$ \\
$\mathbf{I}$ & $\mathrm{NO}_{2}$ & $10.84 \mathrm{ppm}$ & $9.39 \mathrm{ppm}$ & $9.79 \mathrm{ppm}$ \\
$\mathbf{H}$ & $\mathrm{NO}_{3}$ & $10.70 \mathrm{ppm}$ & $9.34 \mathrm{ppm}$ & $9.77 \mathrm{ppm}$ \\
$\mathbf{F}$ & $\mathrm{SCN}_{\mathbf{N}}$ & $10.50 \mathrm{ppm}$ & $9.16 \mathrm{ppm}$ & $9.76 \mathrm{ppm}$ \\
$\mathbf{C}$ & $\mathrm{BF}_{4}$ & $9.60 \mathrm{ppm}$ & $9.10 \mathrm{ppm}$ & $9.75 \mathrm{ppm}$ \\
$\mathbf{D}$ & $\mathrm{PF}_{6}$ & $9.17 \mathrm{ppm}$ & $8.95 \mathrm{ppm}$ & $9.74 \mathrm{ppm}$ \\
$\mathbf{E}$ & $\mathrm{BPh}_{4}$ & $8.99 \mathrm{ppm}$ & $8.88 \mathrm{ppm}$ & $9.74 \mathrm{ppm}$
\end{tabular}

${ }^{a}$ Measured in at concentrations of $83 \mu \mathrm{mol} \mathrm{mL} \mathrm{m}^{-1}$ and internally referenced to the residual protio-solvent signal at $7.26\left(\mathrm{CDCl}_{3}\right), 1.94$ $\left(\mathrm{CD}_{3} \mathrm{CN}\right)$ and $2.50 \mathrm{ppm}$ (DMSO- $\left.d_{6}\right)$ relative to TMS, respectively. 
Table $3{ }^{13} \mathrm{C}_{\mathrm{C} 2}$ NMR signals of salts $\mathrm{A}-\mathrm{F}, \mathrm{H}, \mathrm{I}$ and $\mathrm{N}$ in different solvents ${ }^{a}$

\begin{tabular}{lllll}
\hline Salt & $\mathrm{X}$ & $\mathrm{CDCl}_{3}$ & $\mathrm{CD}_{3} \mathrm{CN}$ & DMSO- $d_{6}$ \\
\hline $\mathbf{N}$ & $\mathrm{Cl}$ & $142.1 \mathrm{ppm}$ & $140.4 \mathrm{ppm}$ & $139.3 \mathrm{ppm}$ \\
$\mathbf{A}$ & $\mathrm{Br}$ & $141.3 \mathrm{ppm}$ & $139.6 \mathrm{ppm}$ & $139.2 \mathrm{ppm}$ \\
$\mathbf{F}$ & $\mathrm{SCN}$ & $140.5 \mathrm{ppm}$ & $138.7 \mathrm{ppm}$ & $139.0 \mathrm{ppm}$ \\
$\mathbf{B}$ & $\mathrm{I}$ & $140.4 \mathrm{ppm}$ & $138.9 \mathrm{ppm}$ & $139.0 \mathrm{ppm}$ \\
$\mathbf{I}$ & $\mathrm{NO}_{2}$ & $140.3 \mathrm{ppm}$ & $139.3 \mathrm{ppm}$ & $139.0 \mathrm{ppm}$ \\
$\mathbf{H}$ & $\mathrm{NO}_{3}$ & $139.7 \mathrm{ppm}$ & $139.2 \mathrm{ppm}$ & $139.0 \mathrm{ppm}$ \\
$\mathbf{E}$ & $\mathrm{BPh}_{4}$ & $139.6 \mathrm{ppm}$ & $138.2 \mathrm{ppm}$ & $138.9 \mathrm{ppm}$ \\
$\mathbf{C}$ & $\mathrm{BF}_{4}$ & $139.2 \mathrm{ppm}$ & $138.6 \mathrm{ppm}$ & $139.0 \mathrm{ppm}$ \\
$\mathbf{D}$ & $\mathrm{PF}_{6}$ & $138.5 \mathrm{ppm}$ & $138.3 \mathrm{ppm}$ & $139.0 \mathrm{ppm}$
\end{tabular}

${ }^{a}$ Measured in at concentrations of $83 \mu \mathrm{mol} \mathrm{mL}^{-1}$ and internally referenced to the solvent signal at $77.7\left(\mathrm{CDCl}_{3}\right), 118.3\left(\mathrm{CD}_{3} \mathrm{CN}\right)$ and $39.5 \mathrm{ppm}\left(\mathrm{DMSO}-d_{6}\right)$ relative to TMS, respectively.

influences are most pronounced. Another striking observation is that the chemical shifts for salts $\mathbf{C}, \mathbf{D}$ and $\mathbf{E}$ with weakly coordinating anions are more downfield in DMSO- $d_{6}$ than in $\mathrm{CDCl}_{3}$. Apparently, these shifts are due to hydrogen bonds with the DMSO solvent molecules. This implies that DMSO is a better hydrogen bond acceptor than the $\mathrm{BF}_{4}{ }^{-}, \mathrm{PF}_{6}{ }^{-}$and $\mathrm{BPh}_{4}{ }^{-}$anions, but significantly weaker than the iodide. Consequently, such anion effects cannot be studied in water, which is best known for hydrogen bonds ( $c f$. Fig. 2).

A similar, but less pronounced trend, likely due to the same reasons, is also noted for ${ }^{13} \mathrm{C}_{\mathrm{C} 2}$ NMR signals, which are summarized in Table 3. Again, it is notable that the chemical shift differences become smaller and smaller with increasing polarity of the solvent, i.e. $\mathrm{CDCl} 3: \Delta \delta 3.6 \mathrm{ppm} ; \mathrm{CD}_{3} \mathrm{CN}: \Delta \delta$ $2.2 \mathrm{ppm}$; DMSO- $d_{6}: 0.3 \mathrm{ppm}$.

Recently, ${ }^{1} J_{\mathrm{C}-\mathrm{H}}$ coupling constants in azolium salts have been used to estimate the donating ability of the respective NHC. ${ }^{30}$ However, it was noted that conclusions made did not consider neither anion nor solvent influences on the ${ }^{1} J_{\mathrm{C}-\mathrm{H}}$ values. ${ }^{29}$ In order to address this issue, we decided compare the ${ }^{1} J_{\mathrm{C} 2-\mathrm{H}}$ of the four salts A-D in the aforementioned solvents. The data summarized in Table 4 indicate that anion or solvent influences on the ${ }^{1} J_{\mathrm{C} 2-\mathrm{H}}$ are surprisingly small or even negligible. Salts with different anions show the same coupling constants in the same solvent. When measured in different solvents only marginal changes of $\sim 1 \mathrm{~Hz}$ were observed. Nevertheless, it is still advisable only to compare salts with the same counteranion, where the data was obtained in the same solvent to avoid any unexpected interferences that could lead to misinterpretations in terms of donating ability of the respective NHC.

\section{H/D exchange reactions}

Increased hydrogen-bond acceptor properties of an anion could also better polarize the $\mathrm{C} 2-\mathrm{H}$ bond and therefore increase its acidity, which may be related to the ease of $\mathrm{C} 2-\mathrm{H} / \mathrm{D}$ exchange. To test this notion, the ease of $\mathrm{C} 2-\mathrm{H} / \mathrm{D}$ exchange of the three salts containing $\mathrm{Br}^{-}(\mathbf{A}), \mathrm{I}^{-}(\mathbf{B})$ and $\mathrm{BF}_{4}{ }^{-}(\mathbf{C})$ anions was studied in $\mathrm{CDCl}_{3}$ at ambient temperature with the addition of one equivalent of $\mathrm{CD}_{3} \mathrm{OD}$ as an deuterium source. Salt $\mathbf{A}$ exchanges
Table $4{ }^{1} J_{C 2-H}$ constants of salts A-D in different solvents ${ }^{a}$

\begin{tabular}{lllll}
\hline Salt & $\mathrm{X}$ & $\mathrm{CDCl}_{3}$ & $\mathrm{CD}_{3} \mathrm{CN}$ & DMSO- $d_{6}$ \\
\hline A & $\mathrm{Br}$ & $217.6 \mathrm{~Hz}$ & $216.3 \mathrm{~Hz}$ & $217.6 \mathrm{~Hz}$ \\
B & $\mathrm{I}$ & $217.6 \mathrm{~Hz}$ & $216.3 \mathrm{~Hz}$ & $217.6 \mathrm{~Hz}$ \\
C & $\mathrm{BF}_{4}$ & $217.6 \mathrm{~Hz}$ & $216.3 \mathrm{~Hz}$ & $217.6 \mathrm{~Hz}$ \\
D & $\mathrm{PF}_{6}$ & $217.6 \mathrm{~Hz}$ & $216.3 \mathrm{~Hz}$ & $217.6 \mathrm{~Hz}$
\end{tabular}

${ }^{a}$ Measured in at concentrations of $83 \mu \mathrm{mol} \mathrm{mL}^{-1}$ and internally referenced to the solvent signal at $77.7\left(\mathrm{CDCl}_{3}\right), 118.3\left(\mathrm{CD}_{3} \mathrm{CN}\right)$ and $39.5 \mathrm{ppm}\left(\mathrm{DMSO}-d_{6}\right.$ ) relative to TMS, respectively.

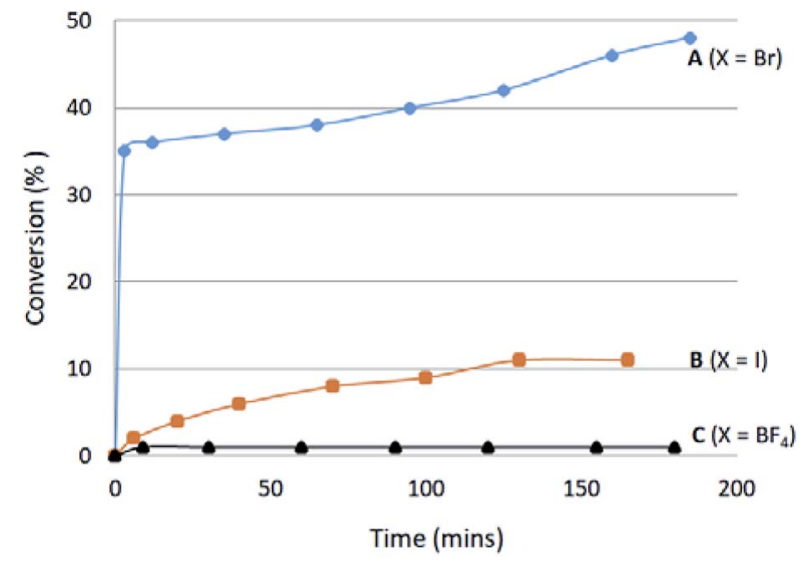

Fig. 7 Time-dependant H/D exchange of salts A-C.

rapidly to give $>30 \%$ conversion in seconds, after which the rate drops significantly (Fig. 7). After 18 hours, 68\% H/D exchange was noted for the bromide salt A. The iodide salt $\mathbf{B}$ shows an extremely slow H/D exchange leading to only $11 \%$ conversion, while almost no H/D exchange was observed for salt $\mathbf{C}$ containing $\mathrm{BF}_{4}{ }^{-}$as the weakest hydrogen-bond acceptor. The very different reaction profiles support an anion influence on the acidity of azolium salts.

Salt $\mathbf{N}$ was expected to undergo H/D exchange with ease. However, it is too hygroscopic to be obtained as a completely water-free salt. Attempts to study the exchange using $\mathbf{N} \cdot \mathrm{H}_{2} \mathrm{O}$ led to an unexpected outcome. Here the $\mathrm{CD}_{3} \mathrm{OD}$ exchanges rapidly with the initial crystal water instead of the less acidic $\mathrm{C} 2-\mathrm{H}$ proton of the benzimidazolium cation.

\section{Conclusions}

We have studied the influences of various anions on the NMR spectroscopic profiles of azolium salts. It was found that the acidic $\mathrm{C} 2-\mathrm{H}$ proton of 1,3-diisopropylbenzimidazolium salts is most sensitive to the nature of the counteranion. The chemical shifts of the $\mathrm{C} 2-\mathrm{H}$ protons allows for a ranking of the anions in terms of their hydrogen-bond acceptor properties, whereby better acceptors affect a more downfield resonance, which could be related to a faster $\mathrm{H} / \mathrm{D}$ exchange. Moreover, it was observed that the $\mathrm{C} 2-\mathrm{H}$ chemical shift differences become significantly smaller with increasing polarity of the solvent, which competes for hydrogen bonding and thus diminishes the effects of the anions. This study also reveals that the ${ }^{1} J_{\mathrm{C} 2-\mathrm{H}}$ 
coupling constants of the azolium salts are almost anion and solvent independent. Since such salts are ubiquitously used as ionic liquids and NHC precursors for organocatalysis and organometallic chemistry, we believe that a better understanding of their anion influences will aid in the studies of their potential applications.

\section{Conflicts of interest}

There are no conflicts to declare.

\section{Acknowledgements}

This work was supported by the National University of Singapore and the Singapore Ministry of Education (WBS R-143-000669-112). Technical support from staff at the Chemical, Molecular and Materials Analysis Centre (CMMAC) of our department is appreciated.

\section{Notes and references}

$1 \mathrm{H} . \mathrm{V}$. Huynh, The Organometallic Chemistry of $\mathrm{N}$-heterocyclic Carbenes, John Wiley \& Sons, Ltd, Chichester, UK, 2017.

2 F. E. Hahn and M. C. Jahnke, Angew. Chem., Int. Ed., 2008, 47, 3122-3172.

3 D. Bourissou, O. Guerret, F. P. Gabbaï and G. Bertrand, Chem. Rev., 2000, 100, 39-92.

4 W. A. Herrmann, Angew. Chem., Int. Ed., 2002, 41, 1290-1309.

5 D. Enders, O. Niemeier and A. Henseler, Chem. Rev., 2007, 107, 5606-5655.

6 L. Benhamou, E. Chardon, G. Lavigne, S. Bellemin-Laponnaz and V. César, Chem. Rev., 2011, 111, 2705-2733.

7 T. L. Amyes, S. T. Diver, J. P. Richard, F. M. Rivas and K. Toth, J. Am. Chem. Soc., 2004, 126, 4366-4374.

8 Y. Chu, H. Deng and J. P. Cheng, J. Org. Chem., 2007, 72, 7790-7793.

9 E. M. Higgins, J. A. Sherwood, A. G. Lindsay, J. Armstrong, R. S. Massey, R. W. Alder and A. C. O'Donoghue, Chem. Commun., 2011, 47, 1559-1561.

10 J. C. Bernhammer and H. V. Huynh, Organometallics, 2012, 31, 5121-5130.

11 H. Sivaram, J. Tan and H. V. Huynh, Organometallics, 2012, 31, 5875-5883.
12 W. Wu, Q. Teng, Y.-Y. Chua, H. V. Huynh and H. A. Duong, Organometallics, 2017, 36, 2293-2297.

13 Q. Teng, W. Wu, H. A. Duong and H. V. Huynh, Chem. Commun., 2018, 54, 6044-6047.

14 H. V. Huynh, Y. Han, J. H. H. Ho and G. K. Tan, Organometallics, 2006, 25, 3267-3274.

15 H. V. Huynh, Y. Han, R. Jothibasu and J. A. Yang, Organometallics, 2009, 28, 5395-5404.

16 S. Guo, H. Sivaram, D. Yuan and H. V. Huynh, Organometallics, 2013, 32, 3685-3696.

17 Q. Teng and H. V. Huynh, Inorg. Chem., 2014, 53, 1096410973.

18 Q. Teng and H. V. Huynh, Dalton Trans., 2017, 46, 614-627. 19 A. G. Avent, P. A. Chaloner, M. P. Day, K. R. Seddon and T. Welton, J. Chem. Soc., Dalton Trans., 1994, 3405.

20 J. A. Cowan, J. A. C. Clyburne, M. G. Davidson, R. L. W. Harris, J. A. K. Howard, P. Küpper, M. A. Leech and S. P. Richards, Angew. Chem., Int. Ed., 2002, 41, 14321434.

21 N. Kuhn and A. Alsheikh, Coord. Chem. Rev., 2005, 249, 829857.

22 P. Bonhôte, A.-P. Dias, N. Papageorgiou, K. Kalyanasundaram and M. Grätzel, Inorg. Chem., 1996, 35, 1168-1178.

23 G. A. Jeffrey and W. Saenger, Hydrog. Bond. Biol. Struct., 1994, pp. 161-163.

24 J.-M. Dumas, M. Gomel and M. Guerin, Halides, PseudoHalides and Azides Part 2, 1983, pp. 985-1020.

25 B. E. Smart, in Organoflourine Chemistry, 1994, pp. 57-88.

26 P. N. Edwards, in Organofluorine Chemistry, 1994, pp. 515520.

27 H.-J. Böhm, S. Brode, U. Hesse and G. Klebe, Chem.-Eur. J., 1996, 2, 1509-1513.

28 J. Van den Broeke, M. Stam, M. Lutz, H. Kooijman, A. L. Spek, B. J. Deelman and G. Van Koten, Eur. J. Inorg. Chem., 2003, 2798-2811.

29 H. V. Huynh, Chem. Rev., 2018, DOI: 10.1021/ acs.chemrev.8b00067.

30 K. Verlinden, H. Buhl, W. Frank and C. Ganter, Eur. J. Inorg. Chem., 2015, 2416-2425. 